\title{
Effect of foods and drinks on primary tooth enamel after erosive challenge with hydrochloric acid
}

\section{Késsia Suênia Fidelis de MESQUITA-GUIMARÃES(a) Camila SCATENA(b) Maria Cristina BORSATTO(a) Antonio Luiz RODRIGUES-JÚNIOR(c) Mônica Campos SERRA ${ }^{(d)}$}

(a) Universidade de São Paulo - USP, School of Dentistry, Department of Pediatric Dentistry, Ribeirão Preto, SP, Brazil.

(b)Faculdade da Serra Gaúcha - FSG, Caxias do Sul, RS, Brazil.

(c) Universidade de São Paulo - USP, School of Medicine, Department of Social Medicine, Ribeirão Preto, SP, Brazil.

(d) Universidade de São Paulo - USP, School of Dentistry, Department of Restorative Dentistry, Ribeirão Preto, SP, Brazil.

Declaration of Interests: The authors certify that they have no commercial or associative interest that represents a conflict of interest in connection with the manuscript.

Corresponding Author:

Késsia Suênia Fidelis de Mesquita-Guimarães E-mail: kessiamesquita@gmail.com

DOI: 10.1590/1807-3107BOR-2015.vol29.0096

Submitted: Oct 23, 2014

Accepted for publication: Apr 13, 2015

Last revision: Jun 29, 2015

\begin{abstract}
The aim of this study was to evaluate the effect of industrialised foods and drinks on primary tooth enamel previously eroded with hydrochloric acid $(\mathrm{HCl})$. The crowns of one hundred two specimens were subjected to an erosive challenge with $\mathrm{HCl}$ and randomly divided into six groups $(\mathrm{n}=17)$ : Chocolate Milk (Toddynho $^{\circledast}$ - Pepsico) - negative control; Petit Suisse Yogurt (Danoninho $^{\circledR}$ - Danone); Strawberry Yogurt (Vigor); Apple puree (Nestlé); Fermented Milk (Yakult ${ }^{\circledR}$ - Yakult); and Home Squeezed Style Orange Juice (del Valle) - positive control. The 28-day immersion cycles for the test products were performed twice daily and were interspersed with exposure of the test substrate to artificial saliva. Measurements of enamel surface microhardness (SMH) were performed initially, after immersion in $\mathrm{HCl}$ and at 7, 14, 21 and 28 days of experimentation. A two-way ANOVA, according to a split-plot design, followed by the sum of squares decomposition and Tukey's test, revealed a significant effect for the interaction between Foods and Drinks and Length of Exposure $(\mathrm{p}<0.00001)$. Orange juice resulted in greater mineral loss of enamel after 28 days. None of the test products was associated with recovery of tooth enamel microhardness.
\end{abstract}

Keywords: Tooth Erosion; Tooth, Deciduous; Hydrochloric Acid; Food; Beverages.

\section{Introduction}

Dental erosion is the chronic loss of tooth substance in the presence of acids, without the involvement of bacteria, ${ }^{1}$ characterised clinically as corrosive-abrasive wear. ${ }^{2}$ It is a multifactorial condition with a complex aetiology and is common in children and adolescents. ${ }^{3}$ It involves contact between acids and tooth structure, which may be due to intrinsic factors such as vomiting, regurgitation, and gastro-oesophageal reflux disease (GORD), and/or extrinsic factors such as industrial sources, ${ }^{4}$ acid medicines, and diet. ${ }^{2}$ Gastro-oesophageal reflux is a physiological process that commonly affects paediatric patients and is characterised by involuntary passage of gastric contents from the oesophagus ${ }^{5}$ into the oral cavity. This is considered pathological when both intensity and frequency increase, causing GORD. ${ }^{5}$ Although the hydrochloric acid $(\mathrm{HCl})$ present in gastric juice induces the demineralisation and loss of dental hard tissues, ${ }^{6}$ diet is the most important cause of dental erosion ${ }^{7}$ due to individuals' high 
consumption of acidic foods and drinks. ${ }^{8}$ The erosive potential of acidic drinks or foods depends on the $\mathrm{pH}$, acid concentration, length of exposure, ${ }^{9}$ titratable acidity, mineral content, clearance on tooth surface, and its calcium-chelating properties. ${ }^{10}$

In seeking to provide practical snacks to children, caregivers often choose manufactured products, including yogurt, fermented milk, petit suisse, fruit puree, juices, and chocolate milk because they are easily transported, well accepted and routinely ingested by children due to their good taste. The literature shows conflicting results regarding the erosive effect of yogurt. Whereas some authors state that yogurt, despite its low $\mathrm{pH}$, does not have an erosive effect, ${ }^{7,8,11}$ a report has shown yogurt significantly increases wear and reduces the hardness of dental enamel. ${ }^{12}$ In a recent study, fermented milk drinks, which are rich in lactobacilli and bifidobacteria and are used in the prevention and treatment of gastrointestinal disorders ${ }_{13}^{13}$ produced enamel mineral loss after four cycles of demineralisation and remineralisation. ${ }^{14}$ Even though there are some studies on food items widely consumed by children, there is a paucity of studies on the effect of petit suisse yogurt, which is fresh cheese derived from milk fermentation and pasteurisation, rich in minerals and vitamins, with the addition of fruit pulp. Pureed Fruit are practical, doughy foods offered to children by the spoonful; however, no studies have evaluated their potential and/or erosive effect. Studies have shown that orange juice has a high erosive potential ${ }^{15}$ and an erosive effect, ${ }^{8,9,11,12,16}$ due to its acidic nature, although it is considered a healthy drink. However, foods and drinks containing milk and, hence, high levels of calcium and phosphate (e.g., chocolate milk) are more likely to have a remineralising effect ${ }^{11}$ on dental enamel. Due to the constant consumption of some industrialised foods and drinks by children and the dearth of literature on this issue, the aim of this paper was to evaluate the erosive effect of yogurt, fermented milk, petit suisse, fruit puree, and orange juice, as well as the remineralising effect of chocolate milk on primary tooth enamel previously eroded by $\mathrm{HCl}$, simulating what occurs in patients with gastro-oesophageal reflux.

\section{Methodology}

This study was independently reviewed and approved by the Research Ethics Committee of the School of Dentistry of Ribeirão Preto, Universidade de São Paulo - USP (Process \#2011.1.1012.58.7).

\section{Composition of foods and beverages and measurement of initial $\mathrm{pH}$}

The information about the compositions of the tested products was obtained from the products' packaging. The $\mathrm{pH}$ of each product was measured with a previously calibrated digital $\mathrm{pH}$ meter (Analion AN2000, Ribeirão Preto, Brazil) (Table 1).

\section{Experimental design}

Arrangements were made to perform a randomised complete block experiment according to a split-plot design in order to compare the response variable (microhardness; $\mathrm{SMH}$ ) and the factors under study (two factors: experimental groups and time effect), as follows:

- Experimental groups - six different types of snacks, foods and drinks for children, including (1) Negative Control [Milk Chocolate (Toddynho $^{\circledR}$ - Pepsico do Brasil Ltda., São Paulo, Brazil)], (2) Positive Control [Orange Juice Home Squeezed Style Orange Juice (del Valle, Sucos del Valle do Brasil Ltda., Santa Bárbara D'Oeste, Brazil)], (3) Apple Puree (Nestlé - Nestlé Brasil Ltda., São Paulo, Brazil), (4) Strawberry Yogurt (Vigor - Vigor Alimentos S.A., São Paulo, Brazil), (5) Fermented Milk (Yakult ${ }^{\circledR}$ - Yakult S.A. Indústria e Comércio, São Bernardo do Campo, Brazil), and (6) Petit Suisse Yogurt $\left(\right.$ Danoninho $^{\circledR}$ - Danone ${ }^{\circledast}$ Ltda., Poços de Caldas, Brazil);

- Time effect - repeated measurements were taken from the same experimental group over time after immersion in $\mathrm{HCl}$ to obtain responses at baseline (before immersion) and at 7, 14, 21, and 28 days after immersion.

Enamel surface loss measured by surface microhardness $(\mathrm{SMH})$ was used as the response variable.

\section{Selection of teeth and preparation of specimens}

Two hundred human primary central incisors were obtained from the Human Tooth Bank of the 
Table 1. Composition and pH of the tested foods and drinks.

\begin{tabular}{|c|c|c|}
\hline Products & Composition* & $\mathrm{pH}^{* *}$ \\
\hline Chocolate Milk Toddynho $^{\circledR}$ & $\begin{array}{l}\text { Reconstituted milk, sugar, whey powder, cocoa, hydrogenated vegetable fat, malt extract, vitamins ( } c \text {, a and } \\
\text { folic acid), salt, thickeners: guar gum and carrageenan, stabilizers: mono and diglycerides of fattly acids, citrate } \\
\text { sodium, and soy lecithin, flavoring. Contains gluten. }\end{array}$ & 6.41 \\
\hline Petit Suisse Danoninho ${ }^{\circledR}$ & $\begin{array}{l}\text { Skim milk, sugar syrup, strawberry mix (water, fructose, strawberry pulp, calcium, phosphorus, sugar, } \\
\text { modified starch, zinc, iron, vitamin } \mathrm{D} \text { and } \mathrm{E} \text {, stabilizers, xanthan gum, carrageenan and carboxymethyl } \\
\text { cellulose, acidulants and tartaric acid citric acid, flavor, potassium sorbate preservative and natural coloring } \\
\text { carmine), cream, calcium chloride, calcium chloride, lactic ferment, chymosin and stabilizers guar gum, } \\
\text { carboxymethylcellulose, carrageenan and xanthan gum. Contains gluten. May contain traces of cashews. }\end{array}$ & 4.27 \\
\hline Strawberry Yogurt & $\begin{array}{l}\text { Skim milk, milk permeate, sugar, buttermilk, prepared strawberry (strawberry pulp, sugar, water, starch, artificial } \\
\text { strawberry flavor, natural dye cochineal carmine, a thickener and stabilizer carrageenan, citric acid acidulant } \\
\text { and potassium sorbate presenvative), modified starch, whey powder and lactic ferment. Artificially flavoured. } \\
\text { Does not contain gluten. }\end{array}$ & 4.19 \\
\hline Apple Puree & Water, apple, apple juice, starch, rice flour, vitamin $C$ and acidulant citric acid. & 3.78 \\
\hline Fermented Milk Yakult ${ }^{\circledast}$ & Skim milk and/or reconstitute skim milk, sugar, glucose, lactic ferment and aroma. Does not contain gluten. & 3.67 \\
\hline Home Squeezed Style Orange Juice & Orange juice, water, sugar, orange pulp, natural flavour, antioxidant, ascorbic acid and acidulant citric acid. & 3.56 \\
\hline
\end{tabular}

School of Dentistry of Ribeirão Preto, Universidade de São Paulo. They were stored in $0.1 \%$ thymol at $4^{\circ} \mathrm{C}$ for $48 \mathrm{~h}$, cleaned with a pumice-water slurry using Robinson bristle brushes, and later examined under a stereomicroscope (Carl Zeiss, Jena, EUA) at 20x magnification, and eventually 78 teeth with cracks or structural anomalies were excluded. Using a low-speed water-cooled diamond saw (Isomet 1000, Buehler, Lake Bluff, Illinois, USA), the teeth were sectioned at the cementoenamel junctions. The crowns were fixed with sticky wax (Kota Ind. Com. Ltda., São Paulo, Brazil) in acrylic resin cylinders $(1.5 \times 1.5 \times 1.0 \mathrm{~cm})$ with the labial surfaces facing up. Grinding and polishing were performed with a water-cooled mechanical grinder (Buehler Beta Grinder Polisher, Lake Bluff, USA) using aluminium oxide abrasive papers (600- and 1200-grit) (Norton Saint-Gobain, São Paulo, Brazil) and a 0.3- $\mu$ m alumina suspension (Buheler, Lake Bluff,, USA). Subsequently, the specimens were ultrasonically cleaned (T1440D, Odontobrás, Ribeirão Preto, Brazil) in deionised water for 10 minutes. The specimens were insulated with a piece of insulating tape, leaving exposed circular areas that were $2 \mathrm{~mm}$ in diameter on each surface, and were subsequently randomly assigned to each experimental group and stored at $37^{\circ} \mathrm{C}$ in $100 \%$ relative humidity.

Prior to the initial microhardness test, the specimens were immersed in artificial saliva as described by McKnight-Hanes and Whitford ${ }^{17}$ and modified according to Amaechi et al..$^{18}$ for $24 \mathrm{~h}$ at $37^{\circ} \mathrm{C}$.

\section{Erosive challenge and immersion cycles}

In an attempt to simulate intrinsic erosive challenge in patients with gastro-oesophageal reflux, each specimen was individually immersed in $10 \mathrm{~mL}$ of $0.01 \mathrm{M} \mathrm{HCl}$ solution ( $\mathrm{pH} 2$ ) for 2 minutes. ${ }^{19}$ They were then washed with deionised water for approximately 10 seconds.

After the erosive challenge with $\mathrm{HCl}$, each specimen was individually immersed in $10 \mathrm{~mL}$ of the test products for $1 \mathrm{~min}$ at room temperature twice daily (at 9 a.m. and 3 p.m.) for 28 days, without agitation. Immediately afterwards, each specimen was washed with deionised water and stored in $10 \mathrm{~mL}$ of saliva for $6 \mathrm{~h}$ (between cycles) and $18 \mathrm{~h}$ (between the first and last cycles on the next day) at $37^{\circ} \mathrm{C}$. The saliva was changed on a daily basis before the first cycle.

\section{Surface Microhardness Tests}

The samples were placed on glass slides in a parallelometer, and three Knoop microhardness indentations (at baseline, after hydrochloric acid $(\mathrm{HCl})$ challenge and at 7, 14, 21 and 28 days of immersion cycles), totalling 18 indentations, were carried out in an HMV-2 microhardness tester (Shimadzu, Kyoto, Japan) (25 g, for $30 \mathrm{~s})$. 
The indentations were separated by a distance of $100 \mu \mathrm{m}$ from the central region of each fragment, allowing $500 \mu \mathrm{m}$ from the top and bottom edges with the aid of Newage Computer Assisted Microhardness System (C.A.M.S.) dedicated software (Newage testing instruments, Inc., Southampton, USA). After the measurements, the specimens whose microhardness values corresponded to $\pm 10 \%$ of the average value were excluded, and 102 specimens were selected and randomly assigned to six groups $(n=17)$.

\section{Statistical Analysis}

The data were analysed by Stata 9.0 software (StataCorp, College Station, USA), and the significance level was set as $\alpha=0.05$. Split-plot ANOVA was used to evaluate the entire dataset at once, considering variance components from repeated measures. Any significant interaction between experimental groups and the time effect was assessed using the sum of squares decomposition followed by Tukey's test.

\section{Results}

ANOVA, with normal distribution, yielded a well-fitted model of data $(\mathrm{R} 2=0.7046)$ and revealed a significant effect concerning the interaction between time and snacks $(\mathrm{p}<0.00001)$, as shown in Table 2. Orange juice resulted in greater enamel mineral loss after 28 days (Figure).

\section{Discussion}

Despite the convenience, durability, and acceptance of processed food and beverages, the acid content in the diet often result in wear, such as dental erosion..$^{10}$ Apart from an acidic diet, erosion is also caused by frequent contact of the oral cavity ${ }^{6,19}$ with $\mathrm{HCl}$, being commonly observed in paediatric patients with gastro-oesophageal reflux. ${ }^{5}$

The proposed protocol to simulate an episode of gastro-oesophageal reflux was adapted from the in vitro model of Hove et al..$^{19} \mathrm{HCl}$, used in intrinsic erosion models,$^{20}$ is a strong acid, ${ }^{21}$ which, in the presence of water, dissociates completely into hydrogen ions and chloride ions, removing the mineral surface. ${ }^{22}$ Short-term acid exposures cause surface changes observed before the loss of tooth structure. ${ }^{23}$ Although there has been a standardisation of the methodology applied in the choice of substrate, size of specimens, polishing procedure, pre-treatment with artificial saliva, baseline microhardness measurements, and volume and duration of acid exposure, this study showed a significant difference across samples exposed to $\mathrm{HCl}$, limiting the comparison of snacks within each time period. If any errors occurred during or after the $\mathrm{HCl}$ challenge, this error was random and it could not be controlled.

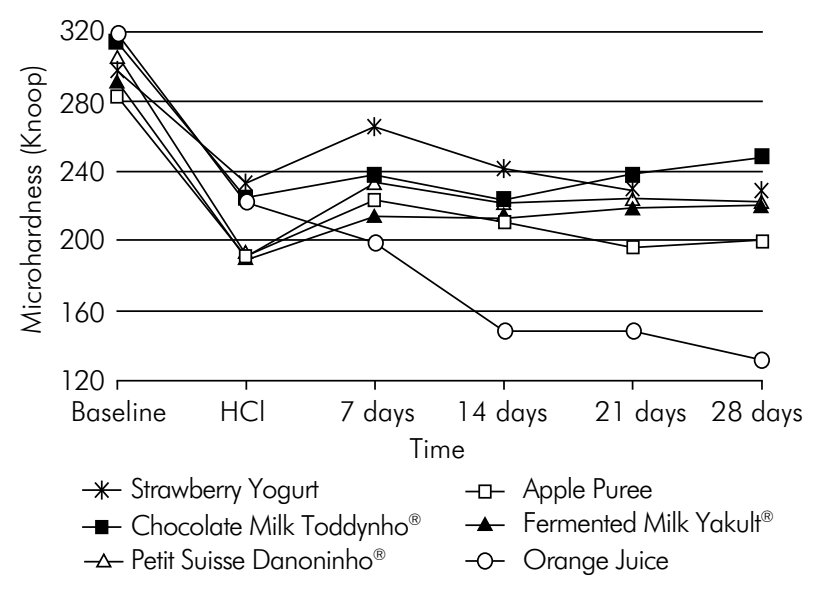

Figure. Mean surface microhardness of each snack according to length of exposure.

Table 2. Mean values and standard deviations of Knoop microhardness at different times of exposure to snacks.

\begin{tabular}{|c|c|c|c|c|c|c|}
\hline \multirow[t]{2}{*}{ Snacks } & \multicolumn{6}{|c|}{ Time } \\
\hline & Baseline & $\mathrm{HCl}$ & 7 days & 14 days & 21 days & 28 days \\
\hline Milk Chocolate Toddynho ${ }^{\circledR}$ & $315.12(49.16)^{\mathrm{Aa}}$ & $224.86(46.65)^{\mathrm{Cab}}$ & $237.55(49.17)^{\mathrm{Cab}}$ & $223.77(46.89)^{\mathrm{Cb}}$ & $238.49(50.62)^{C_{c}}$ & $248.92(51.26)^{C_{c}}$ \\
\hline Petit Suisse Danoninho ${ }^{\circledR}$ & $306.08(47.26)^{\mathrm{Ba}}$ & $193.80(61.94)^{\mathrm{Ca}}$ & $233.53(48.04)^{A a b}$ & $222.05(55.86)^{\text {ACb }}$ & $224.68(52.80)$ ACbc & $223.29(46.80)^{A C b c}$ \\
\hline Strawberry Yogurt & $297.65(44.72)^{\mathrm{Aa}}$ & $232.92(38.69)^{\mathrm{Cb}}$ & $265.55(57.77)^{\mathrm{ACb}}$ & $241.88(40.25)^{\mathrm{Cb}}$ & 229.65 (36.39) Cbc & $229.25(51.34)^{\mathrm{Cbc}}$ \\
\hline Apple Puree & $283.53(56.37){ }^{\mathrm{Aa}}$ & $191.67(50.20)^{\mathrm{Ca}}$ & $223.55(34.71) \mathrm{Ca}$ & $211.23(48.57)^{\mathrm{Cb}}$ & $196.55(29.22)^{\mathrm{Cb}}$ & $200.20(35.24)^{\mathrm{cb}}$ \\
\hline Orange Juice & $318.84(59.22)^{\mathrm{Ba}}$ & $222.88(60.15)^{\mathrm{Aab}}$ & $199.33(36.60)^{\mathrm{Aa}}$ & $148.72(36.89)^{\mathrm{Ca}}$ & $148.98(42.20)^{\mathrm{Ca}}$ & $132.45(39.83)^{c_{a}}$ \\
\hline Fermented Milk Yakult ${ }^{\circledR}$ & $292.49(61.73)^{\mathrm{Aa}}$ & $191.47(59.45)^{\mathrm{Ca}}$ & $214.51(52.53)^{\mathrm{Ca}}$ & $213.51(49.21)^{\mathrm{Cb}}$ & $219.10(51.18)^{\mathrm{Cbc}}$ & $221.10(49.27)^{\mathrm{Cbc}}$ \\
\hline
\end{tabular}

Capital letters indicate comparison in lines and lowercase letters indicate comparison in columns.

Different letters indicate statistical difference $(p \leq 0.05)$. 
Processed foods and beverages, commonly given to infants as snacks, were used, assuming that the diet could interfere in the process of enamel demineralisation and remineralisation already caused by the intrinsic erosive challenge. All the selected products, except for chocolate milk ( $\mathrm{pH}$ 6.41), had $\mathrm{pH}$ levels below the critical $\mathrm{pH}$ for dissolution of hydroxyapatite. ${ }^{7}$ Although Ferreira and Pozzobon ${ }^{23}$ claimed that the $\mathrm{pH}$ of chocolate-based products would not have the potential to cause dental erosion, no studies to date have specifically tested their remineralising effect. Milk-based products may have a protective effect and may not cause enamel demineralisation, depending on their amount of calcium and phosphate. ${ }^{11}$ Cow's milk was found to cause remineralisation of the bovine enamel surface after an erosive challenge with chlorinated water. ${ }^{24}$ Chocolate milk contains calcium and was chosen as a negative control, in the expectation that it could remineralise the tooth surface previously exposed to $\mathrm{HCl}$. The results of this experiment showed that chocolate milk (Toddynho ${ }^{\circledR}$ ) did not remineralise the enamel surface during the study period.

Orange juice was chosen as a positive control due to its erosive potential ${ }^{15}$ and to the presence of citric acid. However, the erosive potential of an acidic drink is not influenced only by the type of acid, but also by its buffering property, chelating property, and frequency and duration of intake. ${ }^{10}$ The erosive effect of orange juice was observed in previous studies ${ }^{8,9,11,14,16}$ by different protocols in relation to volume of liquid, length of exposure, duration of the erosive challenge, and salivary exposure. No study has evaluated the effect of orange juice or other foods and drinks after simulation of an endogenous erosive challenge in primary teeth, as was conducted in this study. Although Torres et al. ${ }^{16}$ evaluated the erosive effect of orange juice on primary enamel and observed surface mineral loss after 45 days, the present study showed that enamel microhardness decreased after only 14 days and remained constant at 21 and 28 days of experimentation. Perhaps, the decrease in enamel microhardness with a shorter length of exposure is justified because the orange juice $(\mathrm{pH} 3.56)$ used in this study was home-squeezed, while the orange juice used by Torres et al. ${ }^{16}$ was soy-based ( $\mathrm{pH} 3.86$ ).
Another possible explanation is the cumulative effect of erosion caused by $\mathrm{HCl}$ challenge, followed by exposure to orange juice containing citric acid. Although it is a weak acid, citric acid chelates calcium from hydroxyapatite ${ }^{18}$ and promotes the dissolution of crystals by binding the hydrogen ion to the carbonate and/or phosphate ion. ${ }^{22}$

Although the manufacturer does not mention the presence of acidulants (e.g., citric acid) or any other acids, fermented milk (Yakult ${ }^{\circledR}$ ) has a $\mathrm{pH}$ of 3.67 and may cause superficial mineral loss in bovine surface enamel after $20 \mathrm{~min}$ of exposure, interspersed with exposure to artificial saliva. ${ }^{14}$ In this study, fermented milk did not exacerbate the mineral loss caused by endogenous simulation challenge at 28 days and by a total exposure of 56 minutes. One possible explanation for this difference would be the greater erosive challenge in Lodi et al., ${ }^{14}$ where dental enamel erosion was assessed using surface microhardness and surface profilometry. Regarding the apple puree, it was expected to decrease enamel microhardness because of its acidic $\mathrm{pH}$ (3.58) and its erosive effect on permanent teeth. ${ }^{25}$ In this study, even after $56 \mathrm{~min}$ of total exposure, the apple puree did not aggravate the mineral loss caused by the $\mathrm{HCl}$ challenge. However, it should be considered that, in this study, the specimens were exposed to apple puree twice daily for $1 \mathrm{~min}$, interspersed with exposure to saliva for about 24 hours. This design was different from the study of Lussi and Jaeggi, ${ }^{25}$ which used one single exposure to apple puree, for 10 or $20 \mathrm{~min}$, not interspersing it with saliva exposure. There are no studies evaluating petit suisse strawberry yogurt, and therefore comparisons are not possible. Although petit suisse yogurt increased enamel microhardness on the seventh day of experimentation, its value was not different from that of $\mathrm{HCl}$ after 14 days of exposure. Although it contains two acids (citric and tartaric acid) and its $\mathrm{pH}$ is below 7, petit suisse yogurt contains calcium and phosphorus in its composition. Some studies have shown that yogurt does not have an erosive effect ${ }^{7,8,11,25}$ on dental enamel. However, there are studies in which yogurt reduced enamel microhardness. ${ }^{12,25}$ Lussi et al. ${ }^{26}$ described that plain yogurt did not cause dental erosion, but the presence of acidic additives in flavoured yogurt 
resulted in a clinically negligible reduction in after 2 min of exposure. In this experimental model, strawberry yogurt ( $\mathrm{pH}$ 4.19) did not reduce the enamel microhardness of primary teeth. In addition to the differences between the types of acids used in the previous challenge, there was also a difference in the type of challenge and in the type of yogurt.

In an attempt to simulate snack time at school, the specimens were submitted to one-minute tests twice a day, interspersed with exposure to artificial saliva, which contains calcium, phosphate and magnesium in its composition and has a similar remineralising effect to that of fresh human saliva. ${ }^{16}$ Considering the lengths of exposure, the option for $2 \mathrm{~min}$ in $\mathrm{HCl}$ and $1 \mathrm{~min}$ in the test products was based on the simulation of in vivo conditions, which should not exceed 2 minutes. ${ }^{20}$ The initial erosive lesions may be caused by acid exposure and shortcycles of exposure to acid, followed by exposure to saliva. ${ }^{20}$ In this test, the initial erosive lesions were produced by simulating the endogenous challenge (i.e., short-term acid exposure) and immersions in test products for $1 \mathrm{~min}$ (i.e., short-exposure cycles). The duration of an in vitro test may range between $15 \mathrm{~s}$ to 40 min per cycle, ${ }^{27}$ depending on the degree of injury desired. Enamel erosion initially manifests itself by partial surface demineralisation due to high mineral content. ${ }^{28}$ In this study, we decided to perform enamel microhardness measurements because they are the most useful method to assess enamel softening. ${ }^{29} \mathrm{In}$

\section{References}

1. Lussi A, Megert B, Shellis RP, Wang X. Analysis of the erosive effect of different dietary substances and medications. Br J Nutr. 2012 Jan;107(2):252-62.

2. Serra MC, Messias DCF, Turssi CP. Control of erosive tooth wear: possibilities and rationale. Braz Oral Res. 2009 Jun;23(Suppl 1):49-55.

3. Lussi A, Schaffner M, Jaeggi T. Dental erosion - diagnosis and prevention in children and adults. Int Dent J. 2007 Dec;57(6):385-98.

4. Addy M, Shellis RP. Interaction between attrition, abrasion and erosion in tooth wear. In: Lussi A. Dental erosion. Monogr Oral Sci. Bern: Basel, Karger; 2006. p.17-21.

5. Davies AEM, Sandhu BK. Diagnosis and treatment of gastro-oesophageal reflux. Arch Dis Child. 1995 Jul;73(1):82-6. addition, this quantitative method is simple, inexpensive, and easily applied, ${ }^{30}$ and consists in measuring the resistance of a substrate to indentation, which can involve Vickers (tetra-pyramidal) or Knoop (rhomboid) measures. ${ }^{28}$ Knoop microhardness was chosen in this experiment because it is considered more sensitive to changes in the surface layer of an erosive lesion ${ }^{27}$ than other microhardness tests.

\section{Conclusion}

Laboratory studies are important for future scientific contributions, despite their limitations and the fact that results may not be conclusive in some clinical situations. Further studies are needed to support definitive conclusions about the erosive potential and effect of chocolate milk, petit suisse strawberry yogurt, strawberry yogurt, apple puree, and fermented milk. However, orange juice should be avoided as a snack option, especially in children exposed to intrinsic acids.

\section{Acknowledgements}

The authors are grateful to Patricia Marchi for technical assistance and to Oficina do Texto for revising the English in the manuscript. This study was supported by Coordenação de Aperfeiçoamento de Pessoal de Nível Superior - CAPES and Conselho Nacional de Desenvolvimento Científico e Tecnológico - CNPq (309219/2009-4).

6. Bartlett D. Intrinsic causes of erosion. In: Lussi A. Dental erosion. Monogr Oral Sci. Bern: Basel, Karger 2006. p.119-39.

7. Lussi A, Schlueter N, Rakhmatullina E, Ganss C. Dental erosion - an overview with emphasis on chemical and histopathological aspects. Caries Res. 2011 May;45(1 Suppl):2-12.

8. Lussi A, Kohler N, Zero D, Schaffner M, Megert B. A comparison of the erosive potential of different beverages in primary and permanent teeth using an in vitro model. Eur J Oral Sci. 2000 Apr;108(2):110-14.

9. Larsen MJ, Nyvad B. Enamel erosion by soft drinks and orange juices relative to their $\mathrm{pH}$, buffering effect and contents of calcium phosphate. Caries Res. 1999 May;33(1):81-7.

10. Lussi A, Jaeggi T. Erosion-diagnosis and risk factors. Clin Oral Investig. 2008 Mar;12(Suppl 1):S5-S13. 
11. Rytömaa I, Meurman JH, Koskinen J, Laakso T, Gharazi $\mathrm{L}$, Turunen R. In vitro erosion of bovine enamel caused by acids drinks and other foodstuffs. Scand J Dent Res. 1988 Aug;96(4):324-33.

12. Jitpukdeebodintra S, Chuenarrom C, Muttarak C, Khonsuphap P, Prasattakarn S. Effects of $1.23 \%$ acidulated phosphate fluoride gel and drinkable yogurt on human enamel erosion, in vitro. Quintessence Int. 2010 Jul-Aug;41(7):595-604.

13. Haukioja A. Probiotics and Oral Health. Eur J Dent. 2010 Jul;4(3):348-55.

14. Lodi CS, Sassaki KT, Fraiz FC, Delbem AC, Martinhon CC. Evaluation of some properties of fermented milk beverages that affect the demineralization of dental enamel. Braz Oral Res. 2010 Jan-Mar;24(1):95-101.

15. Hunter L, Patel S, Rees J. The in vitro erosive potential of a range of baby drinks. Int J Paediatr Dent. 2009 Sep;19(5):325-29.

16. Torres CP, Chinellati MA, Gomes-Silva JM, Rizóli FA, Oliveira MA, Palma-Dibb RG, et al. Surface and subsurface erosion of primary enamel by acid beverages over time. Braz Dent J. 2010 Sep;21(4):337-45.

17. McKnight-Hanes C, Whitford GM. Fluoride release from three glass ionomer materials and the effects of varnishing with or without finishing. Caries Res. 1992; (5):345-50. doi: 10.1159/000261466.

18. Amaechi BT, Higham SM, Edgar WM. Factors influencing the development of dental erosion in vitro: enamel type, temperature and exposure time. J Oral Rehabil. 1999 Aug;26(8):624-30.

19. Hove LH, Holme B, Øgaard B, Willumsen T, Tveit AB. The protective effect of TiF4, SnF2 and NaF on erosion of enamel by hydrochloric acid in vitro measured by white light interferometry. Caries Res. 2006 Sep;40(5):440-43. doi: 10.1159/000094291.
20. Young A, Tenuta LMA. Initial erosion models. Caries Res. 2011 May;45(1 Suppl):33-42.

21. West NX, Hughes JA, Addy M. The effect of $\mathrm{pH}$ on the erosion of dentine and enamel by dietary acids in vitro. J Oral Rehabil. 2001 Sep;28(9):860-64.

22. Featherstone JD, Lussi A. Understanding the chemistry of dental erosion. In: Lussi A. Dental erosion. Monogr Oral Sci. Bern: Basel, Karger 2006; p.66-76.

23. Ferreira FV, Pozzobon RT. Processed dairy beverages $\mathrm{pH}$ evaluation: consequences of temperature variation. J Clin Pediatr Dent. 2009 Summer;33(4):319-24.

24. Vongsawan K, Surarit R, Rirattanapong P. The effect of high calcium milk and casein phosphopeptide-amorphous calcium phosphate on enamel erosion caused by chlorinated water. Southeast Asian J Trop Med Public Health. 2010 Nov;41(6):1494-99.

25. Lussi A, Jaeggi T. The potential of various oral care products compared to foodstuffs and beverages. Schweiz Monatsschr Zahnmed [Internet]. 2001[cited 2012 Feb 17];111(3):274-81. Available from: http://www.gaba-bv.nl/data/docs/nl_ NL/1186/Studie-Lussi-Jaeggi-2001.pdf

26. Lussi A, Merget B, Shellis RP, Wang X. Analysis of the erosive effect of different dietary substances and medications. Br J Nutr. 2012 Jan;107(2):252-62.

27. Wiegand A, Attin T. Design of erosion/abrasion studies - insights and rational concepts. Caries Res. 2011 May;45(1 Suppl):53-9.

28. Schlueter N, Hara A, Shellis RP, Ganss C. Methods for the measurement and characterization of erosion in enamel and dentine. Caries Res. 2011 May;45(1 Suppl):13-23.

29. Barbour ME, Rees JS. The laboratory assessment of enamel erosion: a review. J Dent. 2004 Nov;32(8):591-602.

30. Shellis RP, Ganss C, Ren Y, Zero DT, Lussi A. Methodology and models in erosion research: discussion and conclusions. Caries Res. 2011 May;45(1 Suppl):69-77. 